\title{
ENERGY MONITORING SYSTEM BERBASIS WEB
}

\author{
Novan Zulkarnain \\ Information Systems Department, School of Information Systems, Binus University \\ Jl. K.H. Syahdan No. 9, Palmerah, Jakarta Barat 11480 \\ novan.zulkarnain@gmail.com
}

\begin{abstract}
Government through the Ministry of Energy and Mineral Resources (ESDM) encourages the energy savings at whole buildings in Indonesia. Energy Monitoring System (EMS) is a web-based solution to monitor energy usage in a building. The research methods used are the analysis, prototype design and testing. EMS consists of hardware which consists of electrical sensors, temperature-humidity sensor, and a computer. Data on EMS are designed using Modbus protocol, stored in MySQL database application, and displayed on charts through Dashboard on LED TV using PHP programming.
\end{abstract}

Keywords: energy monitoring system, Modbus, MySQL, PHP

\begin{abstract}
ABSTRAK
Pemerintah melalui Kementrian Energi Dan Sumber Daya Mineral (ESDM) menganjurkan adanya penghematan energi pada seluruh gedung di Indonesia. Energy Monitoring System (EMS) berbasis Web merupakan salah satu solusi untuk memonitor penggunaan energi pada sebuah bangunan. Metode penelitian yang digunakan adalah analisis, perancangan prototype dan testing. EMS terdiri dari perangkat keras yang terdiri dari sensor listrik, sensor temperatur-humidity, dan komputer. Data pada EMS dirancang menggunakan protokol Modbus, yang datanya disimpan pada aplikasi database MySQL, dan kemudian ditampilkan dengan Dashboard berupa grafik pada LED TV dengan menggunakan pemograman PHP.
\end{abstract}

Kata kunci: energy monitoring system, Modbus, MySQL, PHP 


\section{PENDAHULUAN}

Menurut data dari Kementrian Energi dan Sumber Daya Mineral (ESDM) penggunaan energi listrik per tahun selalu mengalami peningkatan. Penggunaan energi digunakan di berbagai sektor industri, rumah tangga, komersil, transportasi dan sektor lainnya. Di akhir tahun 2010 penggunaan untuk energi listrik mencapai 90.35 Milyar BOE (barrel of oil equivalents) (ESDM, 2011).

Kementrian Energi Dan Sumber Daya Mineral (ESDM) telah mendesain salah satu lantai gedung dengan konsep hemat penggunaan energi. Untuk mengetahui apakah lantai tersebut memang "Hemat energi", maka diperlukanlah sebuah sistem monitoring. Sistem ini menggunakan alat sensor energi listrik yang dipasang pada Control Panel Box dan terhubung dengan semua perangkat listrik yang ada di lantai itu. Untuk mengetahui penggunaan listrik setiap hari sangatlah sulit, karena hanya dapat dilakukan dengan melihat pada monitor kecil pada alat sensor tersebut, sehingga memakan waktu dan tenaga.

Dengan perkembangan teknologi saat ini, khususnya teknologi informasi dan telekomunikasi berbasis Web sangatlah memberikan peranan penting bagi kemudahan dan fasilitas. Seluruh tugas dan kegiatan dapat diselesaikan tanpa harus memakan waktu lama dan tenaga yang menguras fisik (Shelly \& Rosenblatt, 2011).

Maka dari itu, pembuatan Energy Monitoring System (EMS) yang berbasis Web merupakan penyelesaiannya, data yang diambil dari sensor dapat dilihat langsung pada layar monitor ataupun alat tampilan lainnya. Aplikasi EMS ini dapat menghitung secara otomatis semua perhitungan penggunaan energi listrik dan menghasilkan tampilan dalam bentuk grafik sehingga dapat dianalisis hasilnya. Keakuratan tampilan sangat tergantung dari masukkan data yang dibaca dari sensor energi listrik. Untuk itu diperlukan protokol komunikasi data yang menghubungkan antara sensor energi listrik dengan database pada komputer kita. Hasil yang diharapkan akan berguna dan membantu program pemerintah.

\section{METODE}

Perancangan dilakukan dengan Metode Analisis, Perancangan dan Testing. Analisis pertama yang dilakukan adalah mempelajari denah gambar dari lantai tersebut (Gambar 1). Dari denah dapat diketahui letak Power Control Panel dan letak sensor temperatur - humidity. Kemudian dilakukan wawancara terhadap pengguna mengenai perhitungan dan beberapa istilah yang terdapat di dalam pengukuran energi listrik.

Pada lantai tersebut terdiri dari 6 sensor listrik dan 8 sensor temperatur - humidity. Sensor listrik dibagi menjadi 3 bagian yaitu, 1 sensor AC ( Air Conditioner), 3 sensor Lampu, dan 2 sensor Plug (Gambar 2). Setelah hasil analisis dari denah dan jumlah sensor yang ada, maka langkah selanjutnya adalah membuat desain dari sistem yang baru.

MODBUS adalah sebuah aplikasi protokol yang bekerja pada layer messaging untuk komunikasi client/server antara perangkat yang terhubung pada sebuah jaringan yang berbeda - beda (Modbus-IDA, 2006). MODBUS secara defacto merupakan aplikasi protokol standar yang digunakan oleh hampir seluruh industri manufaktur. 


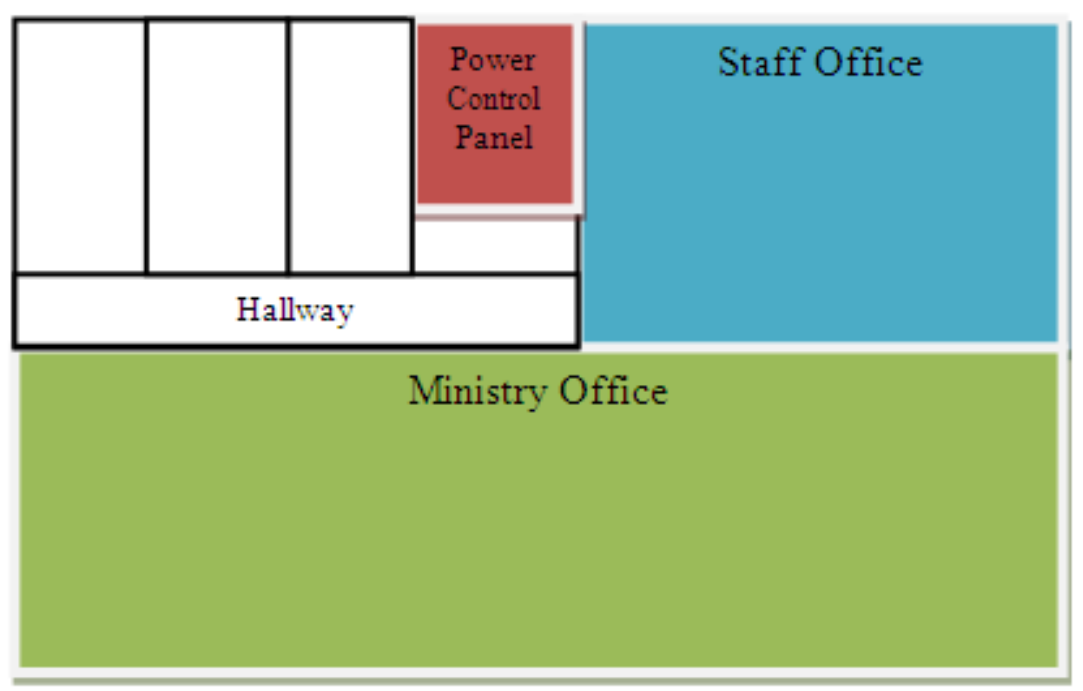

Gambar 1 Denah lantai gedung

MODBUS menggunakan teknik master - slave, di mana di antara kedua alat yang saling terhubung salah satunya dijadikan master-nya dan alat lainnya dijadikan slave-nya. Alat master mengirimkan permintaan berupa queri dan alat slave merespon permintaan tersebut dan mengirimkan kembali data yang diminta dari queri master. Alat slave dapat berupa perangkat apapun baik itu alat komunikasi, sensor, alat pengukuran dan lain - lain yang dapat mengirimkan informasi dan mengirimkan ke alat master dengan MODBUS (Modbus-IDA, 2006).

Structured Query Language (SQL) merupakan bahasa standar ANSI (American National Standards Institute) yang digunakan untuk melakukan Query data pada basis data (Fehily, 2010). SQL memungkinkan semua pengoperasian data dapat dikerjakan dengan mudah sekali. Singkatnya, dengan adanya SQL maka pengelolaan Basis Data menjadi semakin mudah dilakukan (Beaulieu, 2009). Struktur SQL cukup sederhana sekali, sehingga sangat mudah untuk dipahami. Di dalam penerapannya pada basis data, SQL digolongkan menjadi tiga kategori, yaitu : Data Definition Language (DDL), Data Manipulation Language (DML), serta Data Control Language (DCL) (Taylor, 2007).

\section{HASIL DAN PEMBAHASAN}

Energy Monitoring System (EMS) dirancang agar dapat diakses melalui Web dan juga dimonitor melalui berbagai perangkat monitoring (LED TV, PC Monitor, Laptop dll). Gambar perancangan dapat dilihat pada Gambar 2. Data diambil dari sensor energi listrik dan sensor temperatur-humidity. Kemudian sensor (slave) terhubung dengan komputer server (master) dengan menggunakan aplikasi protokol MODBUS.

MODBUS menghubungkan komunikasi antara sensor dengan komputer server dengan menggunakan kabel RS232. Di mana di dalam komputer server telah terinstall protokol yang dapat membaca data dari MODBUS dan memasukkannya ke dalam data pada MySQL. Data dibaca setiap 15 detik untuk mengetahui pergerakkan secara Real-Time, dan setelah 20 menit data di-backup dan disimpan pada MySQL. 


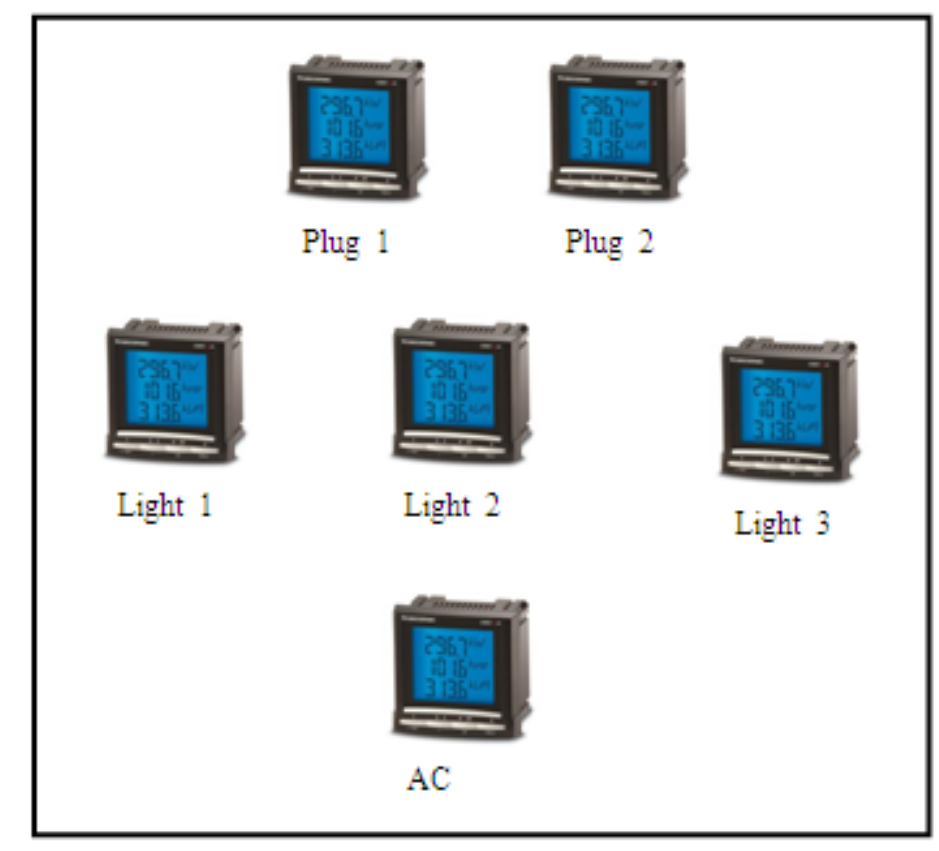

Gambar 2 Power monitoring sensor

Untuk tampilan grafik digunakan aplikasi open source PHP, yang disimpan pada komputer server dengan aplikasi server-nya adalah Apache. Struktur navigasi ditentukan sesuai dengan keinginan pengguna seperti terlihat pada Gambar 3.

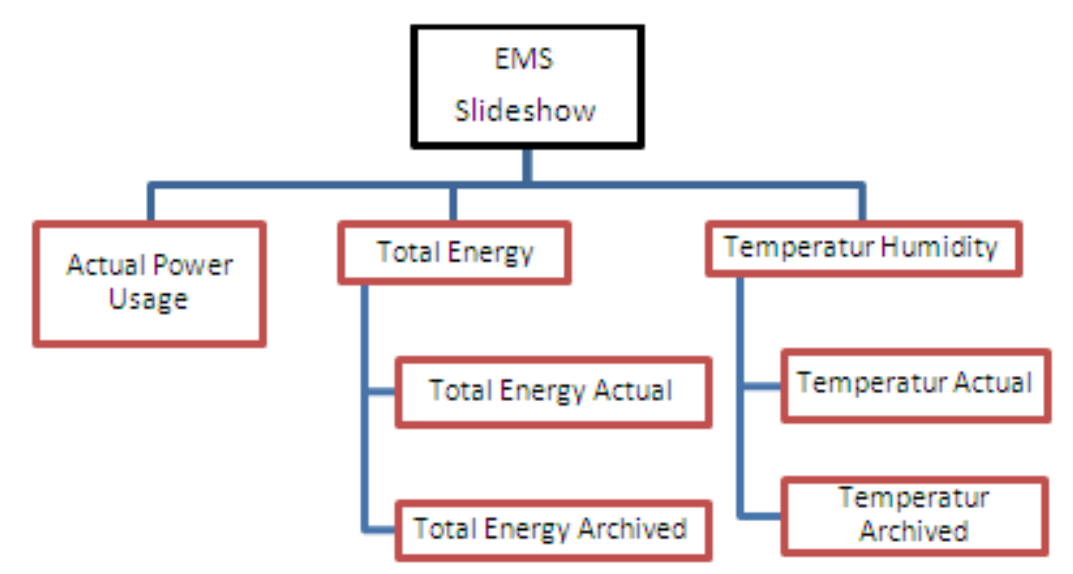

Gambar 3 Struktur navigasi web EMS

Prototype EMS yang telah selesai kemudian diimplementasikan pada sistem jaringan komputer. Selanjutnya, seluruh data dummy dimasukkan. Tahapan terakhir setelah semua telah dinyatakan benar adalah testing di mana pengguna dari seluruh pembangkit listrik mendaftarkan dan memasukkan data dari hasil pengendalian pada masing-masing lokasi. Berikut adalah contoh dari antarmuka pada saat dilakukan testing (Gambar 4-8). 


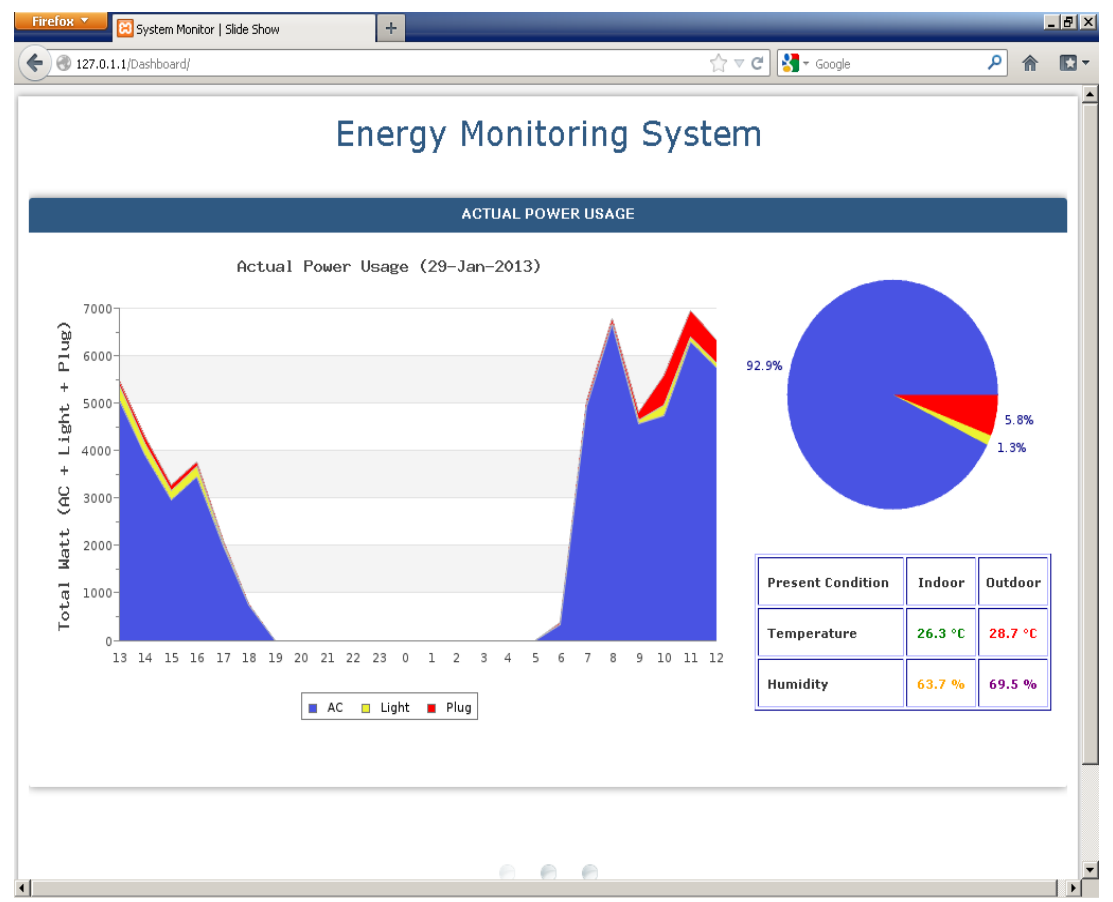

Gambar 4 Tampilan halaman Actual Power Usage

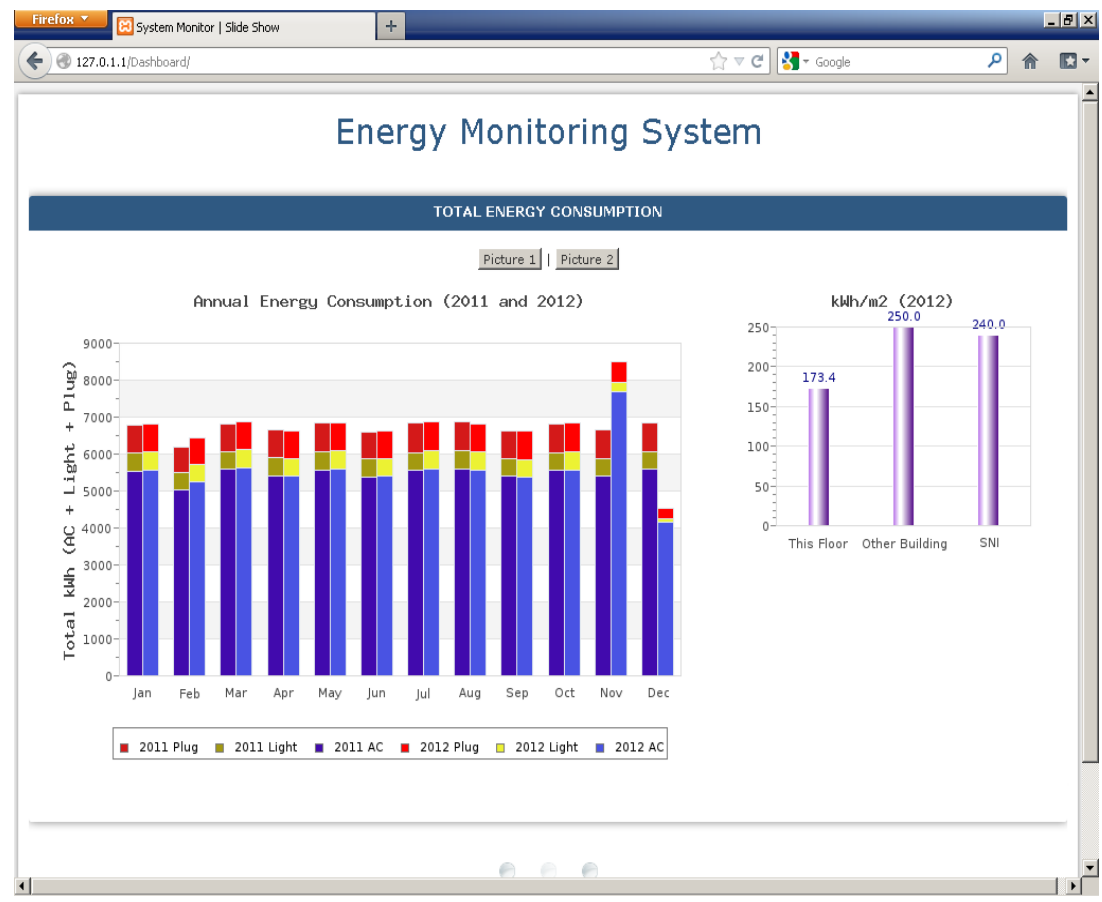

Gambar 5 Tampilan halaman Total Energy Actual 


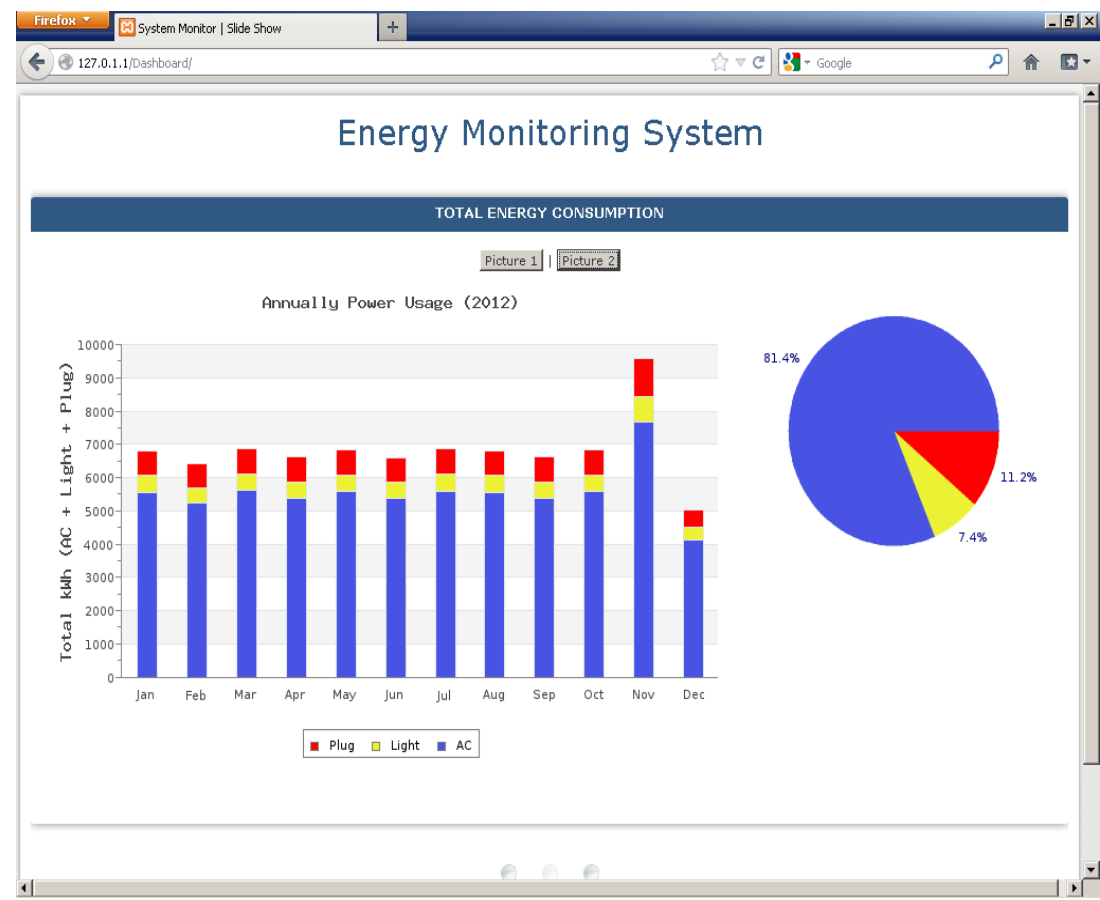

Gambar 6 Tampilan halaman Total Energy Archived

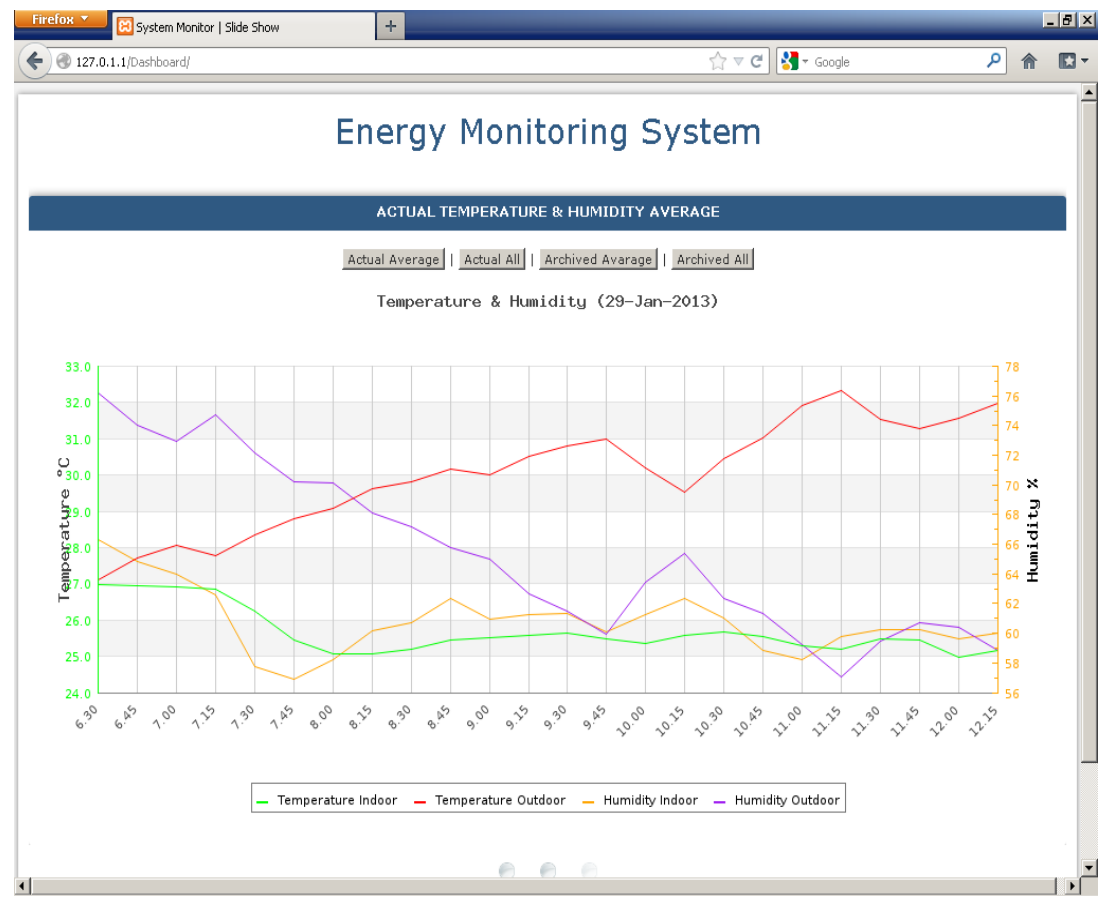

Gambar 7 Tampilan halaman Temperature Actual 


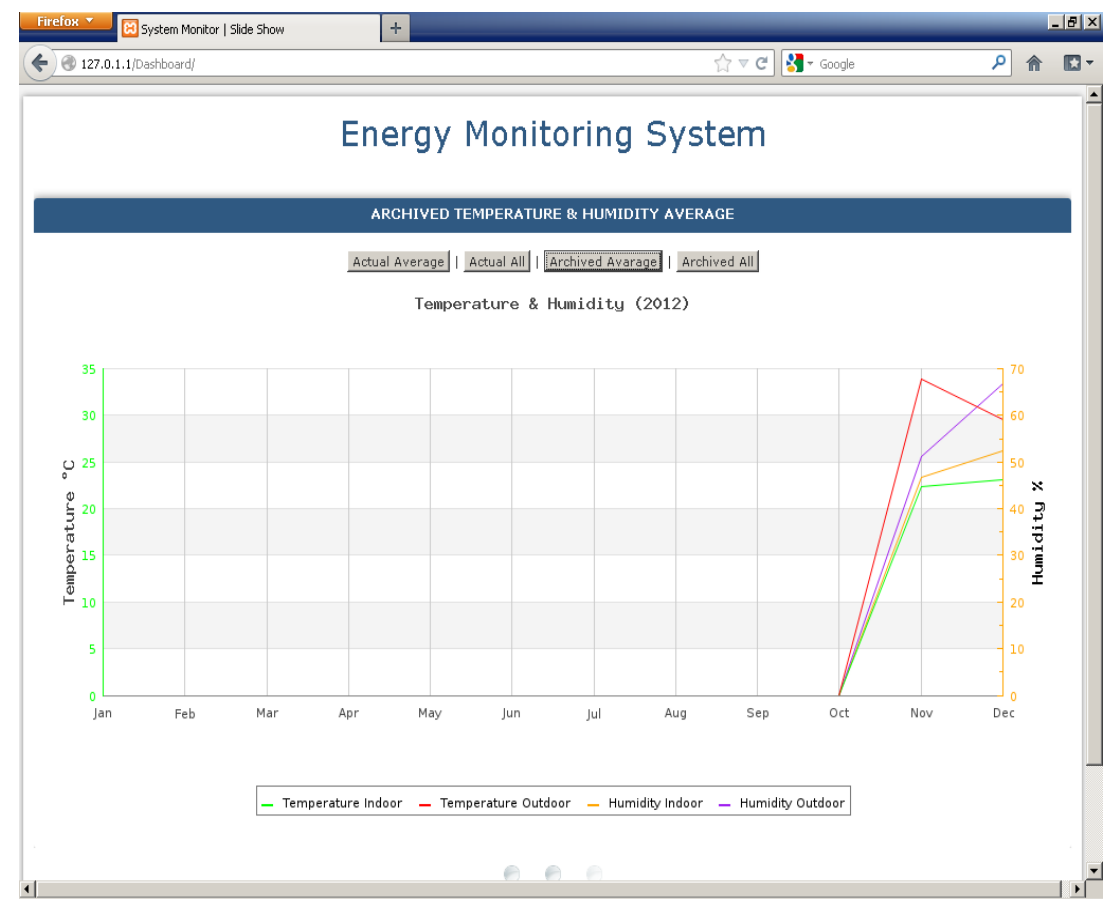

Gambar 8 Tampilan halaman Temperature Archived

\section{PENUTUP}

Penelitian yang dilakukan telah berhasil membangun Prototype Energy Monitoring System (EMS) Berbasis Web. EMS dapat pengukur penggunaan energi listrik dan temperature-Humidity pada lantai gedung ESDM. Dengan menggunakan EMS terlihat adanya penghematan energy pada lantai gedung ESDM. EMS telah di uji coba dan telah dilakukan pelatihan pada pengguna di Kementrian Energi Sumber Daya dan Mineral (ESDM). Untuk tahapan lebih lanjut diperlukan IP public agar EMS ini dapat diakses dari berbagai tempat.

\section{DAFTAR PUSTAKA}

Kementrian Energi dan Sumber Daya Mineral (ESDM) (2011). Handbook of Energy \& Economic Statistics Indonesia. 10th edition. Jakarta: Kementrian ESDM.

Modbus-IDA (2006). Modbus Application Protocol Specification. Diakses dari http://www.modbus.org/docs/Modbus_Application_Protocol_V1_1b.pdf.

Shelly,G.B., Rosenblatt, H. J. (2011). Systems Analysis and Design. Kentucky: Cengage Learning.

Taylor, Allen G. (2007). SQL All-in-One Desk Reference For Dummies. New Jersey: John Wiley \& Sons. 